\title{
A história social dos cemitérios em Alfenas entre 1902 e 1921
}

\section{The social history of the cemeteries in Alfenas between 1902 and 1921}

\begin{abstract}
Alisson Eugênio*
Resumo: ao longo deste artigo será apresentado uma pesquisa, baseada nos registros de óbitos do município de Alfenas, sul de Minas Gerais, na qual foram confrontadas as causas das mortes e os perfis sociais dos mortos para compreender as condições de saúde pública do referido município. Assim, procurou-se investigar quais eram os problemas de saúde mais mortíferos e quais as parcelas da população eles mais afetavam. Partindo dessas questões, com base na documentação e na historiografia especializada no campo de estudos da história das doenças, da medicina e da saúde, observou-se que grande parte da mortalidade está relacionada com a pobreza, a carência de uma política de saúde pública preventiva e às dificuldades dos saberes médico e farmacêutico para solucionar problemas para os quais eles ainda não estavam preparados.
\end{abstract}

Palavras-chave: registro de óbitos, doenças e desigualdade social.

Abstract: Throughout this article a survey will be presented, based on the death records of the municipality of Alfenas, south of Minas Gerais, in which the causes of the deaths and the social profiles of the dead were confronted in order to understand the public health conditions of that municipality. Thus, an attempt was made to investigate which were the most deadly health problems and which parts of the population they affected the most. Based on these questions, based on documentation and specialized historiography in the field of studies of the history of diseases, medicine and health, a large part of the mortality was related to poverty, the lack of a preventive public health policy and the difficulties of medical and pharmaceutical knowledge to solve problems for which they were not yet prepared.

Keywords: register of deaths, diseases and social inequality.

\footnotetext{
* Doutor em história econômica pela Universidade de São Paulo - USP e pós-doutor pela Universidade Federal de Minas Gerais -UFMG. Professor de História do Brasil na Universidade Federal de Alfenas.
} 


\section{Introdução}

A partir das décadas finais do século XX, o estudo da história das doenças vem crescendo vertiginosamente no Ocidente como resultado, entre outros fatores, da renovação das bases e da expansão temática do saber historiográfico promovida pela Escola dos Annales desde 1929, o que foi possível, em grande parte, pelo estreitamento dos laços entre os historiadores influenciados por tal escola e as Ciências Sociais.

Esse estreitamento vem gerando um diálogo cada vez mais profícuo para ambos campos de conhecimento, gerando consequentemente uma ampliação do leque de possibilidades de investigação dos mais diversos tipos de objetos, como os derivados da área de estudos que abrangem a saúde pública.

Esse fenômeno intelectual também está em curso no Brasil e pode ser constatado pela criação de vários grupos de pesquisa especializados no campo de estudos das doenças, da Medicina e da saúde, pelo surgimento de programas de pós-graduação concentrados nesta especialidade, pela organização de diversos eventos nela inspirados e pela elaboração de inúmeras monografias, dissertações e teses, bem como pela publicação de artigos, capítulos de livro e livros, dedicadas a objetos dela derivados. ${ }^{1}$

Com a diversificação de temas aberta por este fenômeno, novas fontes de estudos passaram a ser valorizadas pelos estudos históricos. Uma delas são as de natureza seriada, como os registros dos cemitérios públicos que servem de base documental para esta pesquisa, cujo recorte geográfico é o município de Alfenas, situado no sul de Minas Gerais, onde há algum tempo uma documentação valiosa, que permite o estudo da história social das doenças foi repassada, sob custódia, à Universidade Federal de Alfenas, para ser organizada, catalogada e conservada no seu Centro de Documentação Histórica (EUGÊNIO, 2013).

\footnotetext{
${ }^{1}$ Dada a enorme quantidade de grupos, eventos, programas, monografias dissertações, teses, artigos, capítulos de livro e livros dedicados a objetos derivados do campo de estudos historiográficos das doenças, da medicina e da saúde, fica impossível apresentá-los nesta nota. Para aqueles que têm interesse maior sobre isso, sugiro a consulta do banco de dados da Fundação Oswaldo Cruz, onde há um programa de pós-graduação especializado em tal campo historiográfico e uma revista (História, Ciência Saúde - Manguinhos) a ele dedicada. Sugiro também a leitura da obra organizada por CHALOUB, 2003, do dossiê organizado por FIGUEIREDO, 2004, dos quatro volumes publicados, por NASCIMENTO et al, 2004, 2006, 2010 e 2013 e a introdução de EUGÊNIO 2012.
} 
Tal município foi emancipado de Caldas em 1860. A povoação que o resultou é fruto da expansão das fronteiras coloniais, pelo bandeirantismo paulista, ao longo do século XVII para além da serra da Mantiqueira e à arrancada econômica impulsionada pelas oportunidades abertas durante a reorientação econômica mineira, ocorrida na segunda metade do século XVIII, quando a economia sulmineira ampliou sua articulação com mercados consumidores externos à Capitania, resultando na criação da Vila de Campanha do Rio Verde, desmembrada de São João Del Rey em 1798 (LENHARO, 1979, e SAES et al, 2012).

O acervo acima mencionado reúne uma documentação datada desde a emancipação do município até a década de 1980. Uma de suas séries documentais são os registros de óbitos de cemitérios municipais, nos quais são registrados nome, idade, sexo, cor, estado civil, causa da morte e, às vezes, a condição social do morto (indigente, pobre, vivia nas ruas, ex-escravo ou escrava, etc.) e o local da morte.

Tais informações estão sistematicamente apresentadas em uma série documental que cobre aproximadamente três décadas (1902-1929). Desse período foram utilizados três registros: 1902-1904 (sede do município), 19081921 (distrito de Fama) e 1921-1929 (distrito Serrania) que revelam, além das doenças que flagelavam a sociedade, aspectos da própria situação social responsável pela criação das condições propiciadoras da mortalidade da época e a sua relação com o perfil dos mortos, como será mostrado a seguir.

Os cemitérios de tal recorte cronológico foram, como os demais de mesma natureza (pública e laica) construídos sob o impacto das pressões do movimento higienista, ou sanitarista, oitocentista encabeçado principalmente por médicos, destinado a sanear o meio urbano e visando à redução dos altos índices de mortalidade provocados por epidemias originadas, segundo as teorias médicas predominantes no século XIX, da má situação sanitária do país, em particular das suas cidades (HOCHMAN, 1998).

Filho da Ilustração, esse movimento começou na Europa em finais do século XVIII. Daí espalhou-se pelo mundo à medida que o ideário de seus protagonistas foi sendo assimilado pelas nações, cujas elites intelectuais, médicas e políticas foram influenciadas pelo pensamento ilustrado, como no Brasil (EUGÊNIO, 2012). Um de seus alvos estratégicos foi a morada dos 
mortos. Aqui, desde a vinda da família real para o Rio de Janeiro em 1808, sua nova sede até 1821, há diversos escritos médicos aconselhando a Coroa a impedir os enterramentos dentro ou nos arredores das igrejas (costume consolidado desde a Alta Idade Média e, desde então, enraizado nas práticas culturais) e afastá-los para locais distantes das povoações, em lugares elevados e bem ventilados. ${ }^{2}$

$\mathrm{Na}$ sede municipal de Alfenas, em 1850 foi construído o primeiro cemitério com base em tais aconselhamentos, segundo um estudioso da história local. Sua localização coincide com o espaço ocupado atualmente pelo fórum da cidade, de onde acabou sendo removido com a expansão urbana impulsionada no início do século XX (RIBEIRO, 2006, p. 41). Ao longo da Primeira República, alguns distritos, como Fama e Água Limpa (Serrania), também passaram a abrigar cemitérios, à medida que suas populações foram crescendo e assimilando os novos costumes, higienizados, a respeito das práticas de sepultamento recomendadas pelo movimento sanitarista.

Nesse novo contexto, a morte já havia perdido aquela aura sagrada de que era revestida desde tempos imemoriais e já estava esvaziada daqueles rituais barrocos, que fundamentavam seu conteúdo dramático e, ao mesmo tempo, apoteótico. Vivia-se em uma época dessacralizada, com uma presença cada vez mais intensa da ciência na vida cotidiana, em particular o saber médico, cuja aproximação com o Estado concorreu para transformar aos poucos os principais problemas de saúde em um tema central da agenda pública.

Assim, os registros de óbitos deixaram de ser feitos nas igrejas e passaram para os cartórios, o que no Brasil ocorreu com o advento da República. Nas localidades, a administração dos cemitérios também registrava os dados dos mortos, com base nas certidões de óbito apresentadas pelo requerente do sepultamento. Grande parte delas, para ser elaborada, utilizou atestado médico, o que confere maior precisão, na maioria dos casos, aos testemunhos obtidos.

Para analisá-los, eles foram agrupados em seções separadas para facilitar a sua exposição e a argumentação que fundamenta as conclusões da pesquisa.

\footnotetext{
2 Há diversos estudos que abordam a cruzada dos movimentos sanitaristas contra os sepultamentos nas igrejas. Entre eles, alguns dos já considerados clássicos, pode-se citar: ARIÈS, 1977 e VOLVELE, 1978. No Brasil há, entre outros, os trabalhos de REIS, 1991, e RODRIGUES, 1997.
} 
Revista Brasileira de História \& Ciências Sociais - RBHCS

Vol. 13 No 26, Janeiro - Junho de 2021

Cada uma delas é dedicada a um tema específico que emerge dos dados: gênero, causas das mortes, mortalidade infantil, mortalidade materna e indigência.

\section{Gênero}

Nos registros de óbitos dos três cemitérios pesquisados estão registradas 2122 pessoas, sendo 1109 homens e 1013 mulheres. A tabela 1 apresenta a distribuição sexual dos mortos por período. Na sede do município de Alfenas, entre 1902 e 1904, foram sepultadas 453 pessoas, 236 homens e 217 mulheres. No Distrito de Fama, entre 1908 e 1921, foram sepultados 529 pessoas, 267 homens e 262 mulheres. No Distrito de Serrania, entre 1921 e 1929, foram sepultadas 1140 pessoas, 606 homens e 534 mulheres.

Tabela 1: Perfil sexual dos mortos

$\begin{array}{cccc}\text { Período } & \text { Homens } & \text { Mulheres } & \text { Total } \\ 1902-04 & 236 & 217 & 453 \\ 1908-21 & 267 & 262 & 529 \\ 1921-29 & 606 & 534 & 1140 \\ \text { Total } & 1109 & 1013 & 2122\end{array}$

\section{As causas das mortes}

Nos cemitérios de Alfenas foram registrados 92 tipos diferentes de causa de mortes (afora a morte natural, os natimortos e as não declaradas).

Tabela 2: Causas das mortes

$\begin{array}{lr}\text { Causa da morte } & \text { Total } \\ \text { Afogado } & 5 \\ \text { Afecção pulmonar } & 4 \\ \text { Anemia } & 1 \\ \text { Aneurisma } & 1 \\ \text { Angina } & 11 \\ \text { Apendicite } & 1 \\ \text { Arterosclerose } & 5 \\ \text { Asfixia } & 3 \\ \text { Assassinado } & 8 \\ \text { Bronquite } & 210 \\ \text { Cancer } & 6 \\ \text { Cancro uterino } & 2 \\ \text { Catarro sufocante } & 13 \\ \text { Cirrose } & 3 \\ \text { Choque elétrico } & 1\end{array}$


Revista Brasileira de História \& Ciências Sociais - RBHCS

Vol. 13 No 26, Janeiro - Junho de 2021

Colerina 27

Congestão cerebral 18

Congestão hepática 2

Congestão 2

Coqueluche 21

Coração 90

Crupe 2

Debilidade* $^{*} \quad 51$

Debilidade senil $\quad 1$

De repente 9

Derrame cerebral $\quad 1$

Diabetes 1

Diarréia 1

Difteria 3

Dispepsia 2

Disenteria 12

Dispepsia 2

Dor na coluna 1

Eclampsia 1

Edema pulmonar $\quad 1$

Enterite 10

Enterocolite 4

Epilepsia 1

Espasmo 1

Febre 12

Febre maligna $\quad 1$

Ferida 2

Fratura do crânio $\quad 1$

Gangrena 1

Gastroenterite $\quad 130$

Gripe $\quad 104$

Hemoptise 7

Hemorragia 5

Hemorragia interna 3

Hérnia 2

Hidropisia 7

Icterícia 2

Inflamação 3

Inflamação hepática $\quad 5$

Infecção intestinal $\quad 182$

Infecção urinária $\quad 1$

Insuficiência

alimentar $\quad 1$

Intoxicação 1

Intoxicação

alimentar 3

Laringite 3

Lombrigas $\quad 1$

Loucura 1

Mal de sete dias 6

Meningite 34 
Revista Brasileira de História \& Ciências Sociais - RBHCS

Vol. 13 No 26, Janeiro - Junho de 2021

$\begin{array}{lr}\text { Miséria fisiológica } & 2 \\ \text { Moléstia cerebral } & 1 \\ \text { Moléstia renal } & 1 \\ \text { Morte natural } & 231 \\ \text { Natimorto } & 198 \\ \text { Não declarada } & 236 \\ \text { Nefrite } & 5 \\ \text { Oftalmia } & 1 \\ \text { Parto } & 33 \\ \text { Picada de cobra } & 3 \\ \text { Pleurisia } & 7 \\ \text { Pneumonia } & 146 \\ \text { Pulmonar } & 6 \\ \text { Queimadura } & 27 \\ \text { Queda de raio } & 2 \\ \text { Renal } & 2 \\ \text { Reumatismo } & 1 \\ \text { Sarampo } & 24 \\ \text { Ś́filis } & 20 \\ \text { Tétano } & 12 \\ \text { Tifo } & 11 \\ \text { Tosse congênita } & 2 \\ \text { Tosse convulsiva } & 1 \\ \text { Toximia } & 1 \\ \text { Tuberculose } & 63 \\ \text { Úlcera estomacal } & 1 \\ \text { Umbigo } & 1 \\ \text { Uremia } & 3 \\ \text { Vermes } & 3 \\ \text { Veneno } & 1 \\ \text { Total } & 2122\end{array}$

* Quando esse termo era usado para identificar crianças nascidas mortas, ou vinha acompanhado de outra expressão, por exemplo dos rins, dos pulmões, etc., optei por contabilizar em natimorto, renal, pulmonar e assim por diante.

Entre as causas de mortes mais freqüentes figuram, em primeiro lugar, as do sistema respiratório. Somando a quantidade de óbitos causados por elas, bronquite (210), pneumonia (146), gripe (104) e tuberculose (63) foram as mais mortíferas ao vitimar 523 pessoas (24,65\%) em total de 2122 registradas.

A explicação para tais moléstias serem muito incidentes está relacionada com a facilidade da sua propagação, o clima frio da região e as precárias condições de vida da maioria da população. Agravante disso é o fato de o Estado, seguindo a orientação liberal triunfante naquele momento de consolidação do capitalismo no Brasil, não assumir a assistência pública à saúde 
como obrigação política, deixando isso a cargo das instituições filantrópicas, a quem ele eventualmente subvencionava (NASCIMENTO, 2013, p 205).

Além disso, a Medicina ainda não tinha grandes recursos para combatêlas (os antibióticos, como a penicilina de Alexander Fleming, descoberta em 1928, somente foram disponibilizados depois da Guerra Mundial de 1939-1945), pois somente aos poucos, ao longo das primeiras décadas do século $\mathrm{XX}$, a teoria da geração espontânea e a origem miasmática das doenças foram dando lugar à teoria da biogênese, originada da descoberta dos microorganismos patogênicos durante a época de Pasteur (1822-1895). Em relação à prevenção, no caso da tuberculose, por exemplo, somente nos anos 1950 a BCG (vacina produzida por Calmette e Guérin no início dos anos 1920) teve sua eficácia reconhecida; depois de quase setenta anos do descobrimento em 1882 do bacilo causador dessa enfermidade por Robert Koch (PORTO, 2004, p. 91 e p. 97).

A gripe, terceira mais mortífera doença acima apontada, normalmente não matava tanta gente. Porém, após a Grande Mundial de 1914 e 1918 estourou uma pandemia conhecida como gripe espanhola responsável pela morte de aproximadamente um terço da população mundial. No Brasil ela fez muitos estragos, conforme revelado por diversos autores (SANTOS, 2004; SILVEIRA, 2004; MARTINS, 2004).

No município de Alfenas, entre outubro de 1918 e final de 1920 pelo menos 50 pessoas (19,45\% das 257 causas de mortes declaradas e 9,45\% das 529 mortes registradas entre 1908 e 1921) foram enterradas no distrito de Fama por causa dela. Há notícias de que ela também afetou o distrito de São Joaquim da Serra Negra, onde medicamentos foram doados aos afetados identificados como pobres. 3 Na sede municipal, sabe-se que no grupo escolar Cel. José Bento foram montados quinze leitos para isolar os doentes e a Escola de Odontologia e Farmácia de Alfenas (a antiga EFOA) ofereceu os seus laboratórios para preparação de remédios contra a doença." 4

Assim, ao que parece, o município foi duramente castigado por tão horrenda epidemia, onde seu bafo exterminador ensejou um espetáculo dantesco, ao desestruturar o cotidiano, diminuindo, senão suspendendo, seu frenético ritmo, com forte impacto nas relações sociais, na dinâmica comercial e

3 Acervo da Prefeitura e da Câmara Municipal de Alfenas (conservado no prédio A da UNIFALMG) CMA 33, avulsos, 22/04/1919.

4 Livro de Atas da Congregação, n. 1, secretaria geral da UNIFAL-MG, 20/10/1918, p. 50. 
na vida de um modo geral, levando seus habitantes a se defrontarem com a angustiante miséria existencial humana, como normalmente ocorre em contextos epidêmicos (DELUMEAU, 1989, p. 121-122).

Nesse mesmo conjunto de moléstias do sistema respiratório, a documentação ainda registra 10 afecções pulmonares, 7 pleurizias, 2 laringites, 2 tosses congênitas, 1 tosse convulsiva e um edema pulmonar, acrescentando 23 mortes às 523 registradas, somando 546 (25,73\%), mais de um quarto das 2122 mortes no período de 1902 a 1929.

O segundo conjunto de doenças mais mortíferas do obituário dos cemitérios alfenenses é formado pela infecção intestinal (182) e gastroenterite (130), que atacam o sistema digestivo. Juntas essas enfermidades mataram 312 pessoas $(14,7 \%)$ das 2122 sepultadas no mesmo período.

Além delas, também atacavam o sistema digestivo as seguintes enfermidades: 27 colerina, 16 enterite e enterocolites, 12 disenteria, 4 verminoses, 3 intoxicação alimentar e 1 diarréia, somando 57 casos ao 312 acima computados, totalizando 376 mortes (17,71\%) entre 2122 pessoas.

Muitas vezes elas são frutos da ingestão de água ou alimentos contaminados com vírus ou bactérias, que provocam inflamação nas paredes do estômago e intestino, ocasionando diarréia, vômitos e fortes cólicas abdominais. $\mathrm{Na}$ época o abastecimento de água nas cidades geralmente se fazia nos chafarizes. Cada um deles era abastecido por um manancial canalizado sem nenhum tratamento. No campo, havia nascentes nas propriedades que eram represadas para uso geral. Era comum também a abertura de cisternas, tanto no meio rural, quanto no meio urbano, para satisfazer a demanda de água. Seja num caso ou no outro, não havia o cuidado de purificá-la, o que aumentava o risco de contaminação.

Em relação aos alimentos, embora os poderes públicos fiscalizassem os estabelecimentos responsáveis pela sua comercialização, havia o problema da sua conservação, que era feita de modo artesanal (refrigeradores domésticos somente começaram a ser fabricados nos anos 1920 nos EUA e não estavam acessíveis, pelo seu alto preço, à maioria da população).

Outro problema: a população não conhecia os microorganismos patogênicos e, consequentemente, não tomava maior cuidado com a assepsia, cuja cultura que a fundamentava estava em processo de construção junto com a 
Revista Brasileira de História \& Ciências Sociais - RBHCS

Vol. 13 No 26, Janeiro - Junho de 2021

consolidação da teoria da biogênese. Por isso, o costume tão banal como nos dias atuais de tomar banho diariamente e lavar as mãos após a evacuação e antes do contato com os alimentos não era generalizado. Como se isso não bastasse, a construção de redes de esgoto apenas estava começando. A maioria das pessoas praticava as necessidades fisiológicas derivadas da excreção em urinóis e despejava os dejetos em fossas construídas nos quintais. Quando não havia quintal na residência, acomodava-os em barris ou outros tipos de recipientes, como se fazia nos tempos da Colônia e do Império, e depois de cheios os esvaziavam nos pontos extremos e inabitados da povoação.

Por essas razões, o resultado não poderia ser diferente: o risco de contaminação da alimentação e da água era muito alto e, a qualquer momento, poderia afetar a saúde humana, provocando sérios estragos, como ocorreu no município de Alfenas, e em todas as sociedades onde tais problemas afetavam a vida cotidiana, durante a Primeira República.

O terceiro conjunto de doenças mais comuns da época é formado pelas enfermidades que atacavam o sistema cardiovascular. A documentação apresenta 90 registros de indivíduos sepultados por causa do coração (dizia-se "morreu do coração", sem especificar a doença) e 11 por causa de angina, resultando 101 mortes $(4,76 \%)$ entre 2122.

Além da predisposição genética e de um estilo de vida propício a esse tipo de enfermidade, os hábitos alimentares são também responsáveis por distúrbios que atacam o sistema cardiovascular. Na época da Primeira República a banha de porco era consumida em grande escala. Como não havia óleo vegetal comestível a baixo preço, a saída era derreter o toucinho, bem picado, em taxo aquecido em alta temperatura (nos tradicionais fogões à lenha). A gordura apurada servia para cozinhar, fritar e conservar alimentos (como a carne depositada em lata ou potes com banha). A pele, extraída antes desse derretimento, cozinhava-se com o feijão e as pelotas de toucinho não derretidas era espremida para se aproveitar o máximo da gordura. O bagaço retirado da espremedora era aproveitado para o preparo de hortaliças refogadas, ou para comer puro mesmo, quando não tinha carne para acompanhar a refeição. Para se ter uma ideia do consumo de toucinho naquela época, ele era o produto com a maior quantidade de negociantes na feira de Alfenas. Somente entre os anos 
Revista Brasileira de História \& Ciências Sociais - RBHCS

Vol. 13 No 26, Janeiro - Junho de 2021

1908 e 1910, 71 toneladas foram ofertadas pelos 288 feirantes cadastrados pelo fisco municipal. 5

Assim, com uma alimentação rica em gordura animal, com elevado grau de saturação de ácidos graxos e glicerol, a população estava muito propensa a atingir alto nível de colesterol, o que para o sistema cardiovascular é muito perigoso como os cardiologistas incansavelmente reiteram.

Enfim, somente as 20 doenças (entre 93 diferentes causas levantadas) acima apresentadas (ou seja, menos de um quarto delas) mataram juntas 1004 pessoas; quase a metade $(47,3 \%)$ das 2122 registradas nos três cemitérios (Sede, Fama e Serrania) do município de Alfenas durante 1902 e 1929.

\section{Mortalidade infantil}

Um dos maiores problemas de saúde pública, principalmente em países onde há grande desigualdade social, como o Brasil, é o alto índice de óbitos de crianças (o a 10 anos). Desde a época colonial, passando pelo período imperial, os dados são alarmantes (VENÂNCIO, 1999, p. 104-110). Em Alfenas, nos cemitérios analisados, dos 2122 indivíduos sepultados, 1354 (63,81\%) foram crianças, sendo 910 (42,88\%) menores de um ano e 444 (20,93\%) maiores de um ano.

Tabela 3: Perfil etário dos mortos

$\begin{array}{llc}\text { Idade } & \text { Total } & \% \\ -1 & 910 & 42,88 \\ +1 & 444 & 20,93 \\ \text { 10 a } 59 & 495 & 23,33 \\ + \text { +o } & 273 & 12,86 \\ \text { Total } & 2122 & 100\end{array}$

Entre as menores de um ano, 198 (21,76\%) nasceram mortos. No conjunto dos sobreviventes ao nascimento, as doenças mais incidentes foram: bronquite 40, infecção intestinal 23, gastrite 20, tétano (ou mal de sete dias) 18 , pneumonia 15, meningite 8 e colerina. Juntas (7 das 18 causas registradas) elas mataram $129(14,17 \%)$ das 910 crianças com menos de um ano de idade.

5 PMA 22.1, Mercado, 1908-1910 (maio de 1908 a abril de 1910). 
Revista Brasileira de História \& Ciências Sociais - RBHCS

Vol. 13 No 26, Janeiro - Junho de 2021

Tabela 4: Principais causas das mortes das crianças menores de 1 ano.

$\begin{array}{lr}\text { Causa da morte } & \text { Total } \\ \text { Natimorta } & 198 \\ \text { Bronquite } & 40 \\ \text { Infecção intestinal } & 23 \\ \text { Gastrite } & 20 \\ \text { Tétano/Mal de } 7 & \\ \text { dias } & 18 \\ \text { Pneumonia } & 15 \\ \text { Meningite } & 8 \\ \text { Colerina } & 5 \\ \text { Total } & 327\end{array}$

Entre as maiores de um ano, as moléstias mais mortíferas foram: 35 de infecção intestinal, 26 de meningite, 21 de coqueluche, 20 de sarampo, 12 de bronquite, 11 de gastrite, 11 de pneumonia. Juntas (7 das 21 causas registradas) elas vitimaram 136 (30,63\%) das 444 crianças com mais de um ano de idade.

Tabela 5: Principais causas das mortes das crianças maiores de 1 ano

$\begin{array}{lr}\text { Causa da morte } & \text { Total } \\ \text { Infecção intestinal } & 35 \\ \text { Meningite } & 26 \\ \text { Coqueluche } & 21 \\ \text { Sarampo } & 20 \\ \text { Bronquite } & 12 \\ \text { Gastrite } & 11 \\ \text { Pneumonia } & 11 \\ \text { Total } & 136\end{array}$

O que explica o alto índice de mortalidade infantil na época é uma combinação de trágica de fatores. Além da extrema desigualdade social, de uma sociedade governada por uma aristocracia que sustentou um modelo de modernização excludente, isto é, com uma concentração de renda nos níveis mais elevados da pirâmide social, dificultando às famílias de baixa renda o acesso aos serviços privados de saúde, ainda havia os problemas culturais e políticos.

O primeiro deles está ligado ao costume de as mulheres darem a luz em casa e sob os cuidados de parteiras. Não havia grande oferta de leitos para obstetrícia nos hospitais. Muitas localidades ficavam distantes deles e também não havia médico suficiente no vasto interior do país, principalmente nas áreas rurais, e mesmo que houvesse, seus preços eram inacessíveis à maior parte da 
população. Além disso, para uma sociedade fortemente marcada pelo machismo, dificilmente uma mulher poderia desnudar-se diante de um obstetra, a não ser em casos de extremo perigo para a parturiente, ou melhor, quando a parteira falhava (geralmente em caso de feto atravessado, ou de ponta a cabeça, ou quando a passagem vaginal estivesse estreita de mais, exigindo cesariana).

Assim, longe das maternidades e sem assistência médica especializada, o risco de morte das crianças, bem como para as mães, era enorme. Por esses motivos, no obituário não só de Alfenas, mas provavelmente em todos os demais municípios no tempo da Primeira República, abundam registros como o de Ana, de idade de 7 dias, branca, falecida no dia 21 de dezembro "de incômodo no umbigo," e o de um feto de cor preta, sexo feminino, filha natural de Emerenciana Maria de Jesus, falecido no dia 12 de dezembro de 1918 "que vai ser sepultado no quadro de pagãos." 6

O segundo deles está ligado a opções políticas de um governo aristocrático, embasado em um liberalismo adaptado à realidade brasileira para defender os interesses da fração de classe que lhe dava suporte no poder, conforme o estudo clássico de Sérgio Buarque de Holanda (1997, p. 160), que em matéria de saúde deixava, exceto em relação às doenças de grande caráter epidêmico (como a febre amarela e varíola) a população entregue à sua própria sorte ou ao sentimento filantrópico de instituições de caridade. Por isso, políticas de acompanhamento das gestantes e de promoção à saúde da criança, que poderiam ter evitado tanta mortandade, não foram colocadas em prática até a chegada de Vargas ao poder, quando novo pacto federativo foi firmado entre as elites e setores organizados da classe média e dos trabalhadores urbanos.

Acresce a esses fatores as limitações do saber médico, marcado pela ausência de métodos preventivos e curativos eficazes contra infecções muito comuns em crianças, como o tétano (a vacina antitetânica, inventada pelo veterinário Gastón Ramón em 1923, somente foi disponibilizada, depois de muita polêmica sobre sua eficácia, na década seguinte e os antibióticos, como a penicilina, inventada por Alexander Fleming em 1928, foi disponibilizada apenas a partir de 1941).

6 PMA 6.1, 1902-1904, Cemitérios p.12 e PMA 6. 2, 1908-1921, Cemitérios, p.25 v. 
A pobreza que afetava grande parte das famílias, em um município próspero, 7 mas, tal como no país de um modo geral, com alta concentração de renda, também ajudou a empurrar muitas crianças para os braços da morte. Indicador disso é a quantidade de crianças de pais considerados muito pobres ou indigentes. Entre 1902 a 1904, dos 119 indivíduos assim classificados 44 (36,97\%) são crianças (tabela 6) e entre 1921 a 1929, dos 84 indivíduos assim classificados 23 (27,38\%) também são (tabela 7), como João, preto, de idade de 7 dias filho de Thobias João da Costa e de Leonina Uberlina de Jesus, muito pobres, falecido no dia 21 de junho de 1902. ${ }^{8}$

Tabela 6: Faixa etária dos indigentes mortos (Sede) 1902-1904

$\begin{array}{lrl}\text { Crianças } & 44 & 36,97 \% \\ \text { Adultos } & 53 & 44,53 \% \\ & & 18,48 \\ \text { Idosos } & 22 & \% \\ \text { Total } & 119 & 100 \%\end{array}$

Tabela 7: Faixa etária dos indigentes mortos (Serrania) 1921-1929

$\begin{array}{lll}\text { Crianças } & 23 & 27,38 \% \\ \text { Adultos } & 37 & 44,04 \% \\ & & 28,57 \\ \text { Idosos } & 24 & \% \\ \text { Total } & 84 & 100 \%\end{array}$

Tudo isso explica em grande parte a enorme tragédia que se abateu sobre as crianças durante a Primeira República, principalmente as menores de um ano (as mais vulneráveis), cuja mortalidade era alta demais mesmo para os padrões aceitáveis da época, conforme mostraram diversos estudos de especialistas neste tema (entre eles, OMRAN, 1977; PALLONI, 1991; SIMÕES, 1997).

Apesar de no Brasil, a partir dos anos 1930, ter ocorrido o que os demógrafos chamam de transição de mortalidade, isto é, redução drástica dos índices de óbitos infantis, graças à razoável melhoria do padrão de vida da

\footnotetext{
7 Segundo o Censo de 1921, o município de Alfenas possuía a $13^{\text {a }}$ maior renda agrícola de Minas Gerais e $5^{\mathrm{a}}$ maior renda proveniente de laticínios. Atlas Geográfico Municipal. V. 1, Belo Horizonte, Imprensa Oficial, 1926, p. 21. Anuário Estatístico de Minas Gerais (baseado no Censo de 1921). V. 3, Belo Horizonte, Imprensa Oficial, 1926, p. 20-25 valores da renda agrícola e p. 200-2005 valores da renda de laticínios. Uma análise de tais dados foi feita por Eugênio (2019, capítulo 3).

8 PMA 6.1, Cemitérios, 1902-1904, p.1
} 
Revista Brasileira de História \& Ciências Sociais - RBHCS

Vol. 13 No 26, Janeiro - Junho de 2021

população, à revolução tecnológica no campo da saúde e ao aumento de estabelecimentos públicos voltados para a assistência médica (FRANÇA e LANSKY, 2008), hoje a diminuição dos índices de mortes de crianças ainda é um grande desafio em países marcados pelo atraso econômico e pela desigualdade social, como o nosso. 9

\section{Mortalidade materna}

Outro grande problema de saúde pública da época foi o alto índice de óbitos de mulheres em gestação, parto e pós-parto. Comparando os registros do início do século XX (1902 A 1904) com os dos anos 1920 (1921 a 1929) no município de Alfenas, observa-se grande percentual de mortes de mulheres com idade fértil (10 a 49 anos). A documentação diz apenas, na maioria dos casos, que "faleceu de parto", sem especificar a causa. Além disso, raramente a documentação permite identificar mortes ocorridas durante a gestação ou no pós-parto, devido à falta de informação complementar. Às vezes, ela afirma que a causa foi eclampsia, hemorragia ou febre puerperal; na atualidade, estas três causas, mais o aborto e o deslocamento prematuro da placenta, são os maiores motivos de óbitos maternos (FERRAZ e BORDIGNON, 2012, p. 527 e 533; SANTOS, 2010, p. 82).

Isso dificulta uma avaliação, com maior exatidão, dos motivos do falecimento. Mesmo assim, apesar dessas limitações documentais, os registros dos cemitérios de Alfenas (tabela 8) revelam que, durante o período de 1902 a 1929, entre as 214 mulheres identificadas nos registros de óbitos com idade fértil, 34 (15,9\%) morreram "de parto."

\footnotetext{
$9 \mathrm{O}$ documento intitulado Evolução e perspectivas da mortalidade infantil. Rio de Janeiro, IBGE, 1999, apresenta dados muito úteis para se comparar o Brasil desde os anos 1930, como a tabela 1 da p. 20, na qual se observa que os índices de mortalidade infantil vêm caindo muito, mais ainda estão altos para os padrões atuais. Neste mesmo documento, na p. 33 o gráfico 4 mostra a evolução do número de estabelecimentos de saúde no país. Nas páginas subseqüentes, 34-36, as tabelas 5 e 6 e os gráficos 5 e 6 mostram o aumento de crianças vacinadas e o da proporção de médicos por habitantes.
} 
Revista Brasileira de História \& Ciências Sociais - RBHCS

Vol. 13 No 26, Janeiro - Junho de 2021

Tabela 8: Óbitos de mulheres com idade fértil e o percentual de mortes provocadas por partos

\begin{tabular}{lrl} 
Período & \multicolumn{1}{l}{$\begin{array}{l}\text { Idade } \\
\text { fértil }\end{array}$} & \multicolumn{1}{l}{$\begin{array}{l}\text { Mortes por } \\
\text { parto }\end{array}$} \\
$1902-04$ & 57 & $13(22,8 \%)$ \\
$1908-21$ & 55 & $1(1,81 \%)$ \\
$1921-29$ & 102 & $20(19,6 \%)$ \\
Total & 214 & $34(15,9 \%)$
\end{tabular}

Trata-se de um percentual alarmante, motivado pela ausência de políticas públicas que disponibilizassem assistência pré-natal e incentivassem as gestantes a se submeteram ao acompanhamento de obstetras e ginecologistas. Aí entra outro problema: além da escassez de profissionais nestas especialidades no vasto interior do país, onde eles estavam disponíveis, os seus preços eram inacessíveis para a maioria da população. E mesmo que fossem baixos, ainda havia o problema cultural, predominante na sociedade da época, sobretudo nas áreas rurais, da interdição do corpo feminino à Medicina, quando se tratava de suas partes mais íntimas.

Afora isso, o saber médico não podia contar com recursos tecnológicos que, a partir dos anos 1940, permitiram a obstetrícia dar largos saltos: os avanços da anestesia que permitiram a cirurgia cesariana ser feita com menor risco e dor, a transfusão de sangue que permitiu o socorro da gestante e parturiente em caso de hemorragia e a invenção dos antibióticos que permitiram o combate às infecções.

Por essa razão, não somente nos óbitos dos cemitérios do município de Alfenas, mas provavelmente em todos os demais municípios no tempo da Primeira República, é muito comum encontrar registro como o de Maria Constância de Jesus, de 40 anos de idade, branca, casada, falecida de parto no dia 16 de novembro de 1902, o de Maria Rita de Jesus, idade de 18 anos, branca, casada, falecida de parto no dia 28 de março de 1904, e o de Antônia Bueno, 15 anos de idade, branca, falecida de febre puerperal no dia 23 de fevereiro de $1923 .{ }^{10}$

Esses registros exemplificam a enorme catástrofe que marcou a história social brasileira da mulher gestante e parturiente durante a Primeira República.

${ }_{10}$ PMA, 6.1, Cemitérios, 1902 a 1904, respectivamente p. 9 e p. 37 e PMA 6.6, 1921 a 1929, Cemitérios, p. 11. 
Quantas vidas perdidas precocemente por causas que poderiam ser evitadas se naquela época houvesse, pelo menos, uma política pública destinada à saúde feminina e à atualização das parteiras (a quem cabia os trabalhos de partos no vasto interior do país) em alguns preceitos médicos essenciais, como maior cuidado com a assepsia. Medidas simples como essas salvariam muitas mães e crianças.

Hoje sabemos que essa história ainda persiste nos países marcados pelo atraso econômico e pela desigualdade social, como o nosso. Embora a realidade atual não seja tão catastrófica como nas décadas iniciais do século passado, ainda há muito a ser feito para nos aproximarmos dos baixos índices das nações mais prósperas e menos desequilibradas socialmente. A esse respeito, um documento do Ministério da Saúde, publicado em 2007 afirma:

\begin{abstract}
A redução da mortalidade materna e neonatal no Brasil é ainda um desafio para os serviços de saúde e a sociedade como um todo. As altas taxas encontradas se configuram uma violação dos direitos humanos de mulheres e crianças e um grave problema de saúde pública, atingindo desigualmente as regiões brasileiras com maior prevalência entre mulheres e crianças das classes sociais com menor ingresso e acesso aos bens sociais. ${ }^{11}$
\end{abstract}

\title{
Indigência
}

Um dos temas mais comoventes da história social, revelada nos registros de óbitos, é o problema da extrema pobreza a qual estava submetida parcela considerável de indivíduos da sociedade brasileira da Primeira República. A nova ordem política inaugurada em 1889, a partir de um processo histórico iniciado com a crise do Império, foi oriunda de uma cisão da classe dominante. Uma nova aristocracia substituía outra no comando do poder, com o apoio dos militares, enquanto o povo assistia a tudo "bestializado". Tratava-se de uma transição pelo alto, ${ }^{12}$ sem participação das camadas populares, em um processo de modernização conservadora, isto é, de transformação na organização política sem mudanças na estrutura social. Afinal, o que estava em jogo era o interesse da nova elite econômica, que se empenhou na construção de um novo pacto político, conhecido como pacto oligárquico (sustentado na política do café com

\footnotetext{
${ }^{11}$ Ministério da Saúde. Manual dos comitês de mortalidade materna, 3 ed. Brasília, Editora MS, 2007, p. 5

${ }_{12}$ Um de nossos mais eminentes historiadores, já em 1936, HOLANDA, 1997, p. 160 afirma: "É curioso notar que os movimentos aparentemente reformadores, no Brasil, partiram quase sempre de cima para baixo".
} 
leite no nível federal, na política dos governadores no nível estadual e no coronelismo no nível municipal) para controlar a máquina do Estado e proteger seus investimentos e interesses de classe. $O$ estado liberal originado desse pacto não contemplou a grande massa da população. Esta continuou entregue à sua própria sorte, ou ao que sobrou da sensibilidade religiosa, expressa na caridade pública, ou à dádiva dos protagonistas da situação política local, ancorada no paternalismo agora na sua manifestação coronelista. ${ }^{13}$

Nesse contexto, a forma como a sociedade brasileira estava estruturada favorecia a proliferação de excluídos sociais, os quais são identificados nos registros de óbitos do município de Alfenas como indigentes. No período de 1902 a 1904, 119 (26,3\%) dos 453 mortos foram assim identificados (tabela 9). No período de 1908 a 1921 os registros não classificaram nenhum falecido como indigente, talvez por uma falha do agente público responsável pelo registro. Já no período de 1921 a 1929, 84 (7,37\%) dos 1140 mortos foram assim identificados (tabela 10). O primeiro período refere-se à sede municipal, predominantemente urbana, e o segundo a um distrito rural. Talvez isso e mais as melhorias materiais oriundas do crescimento econômico posterior à Guerra Mundial de 1914 a 1918 expliquem a queda de um período ao outro. Mesmo com a redução, o percentual de desvalidos ainda era muito grande, o que revela uma sociedade marcada por forte desigualdade social.

$13 \mathrm{O}$ entendimento da transição política acima referida é tomado de COSTA, 1985 cap. 9. A expressão "os bestializados" foi proferida por um senador contemporâneo da proclamação da República, Aristides Lobo, e é usada por CARVALHO para dar título à sua obra, 1996. Já o conceito de modernização conservadora foi formulado por MOORE Jr., 1975, para explicar o modelo de transição política em países, como a Alemanha, onde a burguesia aliou-se com a aristocracia para promover a modernização. O coronelismo, de acordo com NUNES, 1997, foi um fenômeno político resultante da "superposição de formas desenvolvidas do regime representativo a uma estrutura econômica e social inadequadas", na qual o poder público ainda era frágil demais para prescindir do poder privado dos potentados locais para se impor à população (p. 40). 
Revista Brasileira de História \& Ciências Sociais - RBHCS

Vol. 13 No 26, Janeiro - Junho de 2021

Tabela 9: Cor e sexo dos indigentes mortos no município de Alfenas (Sede) 1902-1904

$\begin{array}{lcr}\text { Brancos } & 35,29 \% & 42 \\ \text { Negros } & 36,13 \% & 43 \\ \text { Pardos } & 25,21 \% & 30 \\ \text { Não declarado } & 3,36 \% & 4 \\ \text { Total } & 100 \% & 119 \\ \text { Homens } & 47,9 \% & 57 \\ \text { Mulheres } & 52,1 \% & 62 \\ \text { Total } & 100 \% & 119\end{array}$

Tabela 10: Cor e sexo dos indigentes mortos no município de Alfenas (Serrania) 19021-1929

$\begin{array}{llc}\text { Brancos } & 23 & \begin{array}{c}27,38 \% \\ 23,82\end{array} \\ \text { Negros } & 20 & \% \\ \text { Pardos } & 15 & 17,85 \% \\ \text { Não declarado } & 26 & 30,95 \% \\ \text { Total } & 84 & 100 \% \\ \text { Homens } & 35 & 41,67 \% \\ & & 58,33 \\ \text { Mulheres } & 49 & \% \\ \text { Total } & 84 & 100 \%\end{array}$

No conjunto dos indigentes da sede, 43 tinham a cor negra (36,13\%), 42 branca $(35,29 \%)$ e 30 parda (25,21\%); 4 não tiveram a cor declarada $(3,36 \%)$. Ou seja, a maioria dos indigentes, $73(61,34 \%)$, era composta por negros e pardos (tabela 9). Já no distrito, se forem considerados apenas os mortos com a cor da pele identificada (58 dos 84), 23 brancos (39,65\%), 20 negros (34,48\%) e 15 pardos (25,86\%). Novamente negros e pardos (61,35\%) são a maioria (tabela 10).

Entre eles, nos registros de óbitos constam os falecimentos dos seguintes indigentes: Antônio Fortunato de Oliveira, pardo, idade de 35 anos, solteiro, falecido no dia 24 de julho de 1902 de morte natural, José Antônio do Prado, 38 anos, preto, falecido no dia 7 de maio de 1904 de pneumonia, e Rufina, solteira, preta, 100 anos de idade, falecida no dia 5 de junho de 1923 de insuficiência cardíaca. ${ }^{14}$

14 PMA, Cemitérios, PMA 6.1, 1902 a 1904, respectivamente p. 3 e p. 39 v, e PMA 6.6, 1921 a 1929, Cemitérios, p. 33. 
Muitas vezes os indigentes não tiveram sua filiação e procedência registradas, como Sebastiana Maria de Jesus, preta, idade de 50 anos, solteira, pais ignorados e naturalidade desconhecida, falecida vítima de pneumonia, sem assistência médica, no dia 16 de junho de 1902, na rua do Cabo Verde desta cidade. Ou então seus sobrenomes eram ignorados, como Sebastião de tal, que "percorria as ruas mendigando com dois cachorros", pardo, de idade de 70 anos, dizia ser viúvo, mas não sabia o nome da sua mulher e nem sua naturalidade, falecido de morte natural no dia 13 de abril de 1903. Ou não tinham pai, como Paulina Maria de Jesus, preta, 20 anos, solteira, filha natural de Ambrósia Maria de Jesus, falecida de tuberculose no dia 12 de outubro de 1903. 15

$\mathrm{Na}$ indigência também morreram diversos ex-escravos, vítimas antes de tudo dos efeitos perversos da abolição da escravidão sem uma política de inclusão social, que pudesse criar condições destinadas ao preparo deles para as relações sociais capitalistas de produção. Assim, muitas vezes sem eira e nem beira, vivendo de pequenos trabalhos temporários e da mendicância, acabavam seus dias no espaço público, como "Custódio, que foi da casa do Sr. Antônio José Ávila Borges, preto, de idade de 35 anos mais ou menos, casado com Graciana Eufrásia de Jesus, de quem havia se separado há anos," o qual, "louco e indigente", disseram ter sido "encontrado morto na frente da casa do Sr. José Ignácio dos Reis" no dia 12 de fevereiro de 1903. Muitos deles entregavam-se ao alcoolismo; talvez como um alívio, ou como último recurso para distrair a consciência das condições adversas que uma estrutura social injusta lhes impôs. Este pode ter sido o caso de Antônio da Silva, preto, idade de 70 anos, solteiro, filiação e naturalidade desconhecidas, indigente, falecido de hidropisia, sem assistência médica, no dia 21 de janeiro de 1904 na Água Limpa. Outros tantos, expostos às mais variadas mazelas da vida cotidiana, eram vítimas da violência, como Pedro de tal, de idade de mais ou menos 35 anos, preto, pobre, solteiro, filiação e naturalidades ignoradas, que morreu assassinado no dia 7 de novembro de 1904. ${ }^{16}$

Alguns dos ex-escravos desvalidos, contando somente com a sua própria sorte e com a caridade, que eventualmente lhes atenuava o peso da miséria, eram africanos; gente arrastada para o Brasil até 1850, quando o deslocamento

15 PMA, Cemitérios, 1902 a 1904, respectivamente p. 1 v, p. 18 v e p. 29 v.

16 PMA, Cemitérios, 1902 a 1904, respectivamente p. 15 v, p. 35 e p. 47 v. 
forçado de negros da África para cá (pelo tráfico de escravos) havia sido proibido definitivamente. Entre eles, foram enterrados como indigente Jacinto da costa, idade de 65 anos, viúvo, falecido de morte natural no dia 16 de março de 1903, Claudino de tal, idade de 90 anos, casado, falecido de morte natural no dia 23 de dezembro de 1903, e Joaquim de Jesus, idade de 120 anos, falecido de senilidade no dia 30 de abril de 1923. ${ }^{17}$

No conjunto dos indigentes (tabela 9 e 10 acima apresentadas), nota-se que o gênero feminino predomina, embora nos registros dos cemitérios os homens são a maioria, revelando o quanto as mulheres eram afetadas pela miséria. Assim, na sede do município, entre 1902 e 1904, 47,9\% pessoas do sexo masculino morreram na indigência contra $52,1 \%$ do sexo feminino. Já no distrito de Serrania, entre 1921 e 1929, a diferença aumentou ainda mais, pois 41,67 \% das pessoas do sexo masculino encontravam-se na mesma situação contra $58,33 \%$ do sexo feminino.

Uma das razões para essa discrepância deve-se ao fato de o Estado brasileiro, durante a Primeira República, seguindo fielmente os princípios liberais da Constituição de 1891 que embasou o seu darwinismo social, não ter interferido nas relações entre capital e trabalho. Consequentemente, nada fez a respeito da proteção (previdência) social que pudesse amparar os trabalhadores e suas famílias quando o seu chefe envelhecesse, adoecesse e morresse. Por esse motivo, antes da Era Vargas e da CLT não havia pensão para as viúvas, conforme mostra José Murilo de Carvalho (2001, p. 61- 64). ${ }^{18}$ Por isso, muitas delas acabavam na indigência, como D. Marcelina da Conceição, idade de 80 anos, branca, viúva, natural de Baependi, falecida de bronquite no dia 1 de janeiro de 1903, e Ana Francisca da Paixão, parda, de idade de 50 anos, viúva, natural desta cidade, falecida de morte natural, sem assistência médica, no dia 16 de dezembro. 19

Para se ter uma noção da dimensão deste problema, na sede do município de Alfenas, no período de 1902 a 1904 foram enterradas 12 viúvas, 10,84\% dos 119 indigentes e 10,43\% das 115 mulheres falecidas com idade acima

\footnotetext{
17 Respectivamente PMA, Cemitérios, 1902 a 1904, p. 17 v e p. 32 v, e PMA 6.6, Cemitérios, 1921 A 1929, p. 21.

18 Segundo esse autor, o primeiro sistema de previdência foram as caixas de aposentadoria e pensão surgidas no Brasil em 1923 exclusivamente para os ferroviários, tendo sido esse estendido em 1926 aos funcionários da União.

19 PMA, Cemitérios, 1902 a 1904, respectivamente p. 13 v e p. 32.
} 
Revista Brasileira de História \& Ciências Sociais - RBHCS

Vol. 13 No 26, Janeiro - Junho de 2021

de 10 anos. No período de 1921 a 1929, no distrito rural de Serrania, foram enterradas 6 viúvas, 7,14\% dos 84 indigentes e 1,74\% das 343 mulheres acima de 10 anos. Somando ambos os períodos, das 458 mulheres sepultadas acima de 10 anos, 3,93 \% delas são viúvas indigentes e das 203 pessoas indigentes, 8,87\% delas são viúvas.

Tabela 11: Percentual de viúvas indigentes

\begin{tabular}{lrlll} 
& \multicolumn{2}{l}{ Idade } & & \\
Período & fértil & \multicolumn{1}{l}{ Viúvas } & Indigentes & \multicolumn{1}{l}{ Viúvas } \\
$1902-04$ & 115 & $12(10,43 \%)$ & 119 & $12(10,84 \%)$ \\
$1921-29$ & 343 & $6(1,74 \%)$ & 84 & $6(7,14 \%)$ \\
Total & 458 & $18(3,93 \%)$ & 203 & $18(8,87 \%)$
\end{tabular}

Ao que parece, grande parte delas, por terem sido escravas, optou, para fugir da miséria, por continuar na propriedade de seus ex-senhores, onde possivelmente seus maridos, quando os tinham, trabalharam até o fim da vida, como Maria Joana, idade de 70 anos, africana, viúva, falecida no dia 5 de agosto de 1902, de morte natural, na chácara de Manuel Galdino do Prado, e Romana de tal, preta, idade de 90 anos, viúva, falecida de morte natural nos Rochas no dia 3 de maio de 1904. ${ }^{20}$

Enfim, os registros dos cemitérios de Alfenas indicam que grande parte das mortes foi provocada por doenças que estão associadas à pobreza, a qual assumiu contornos dramáticos no município, dado o alto número de pessoas neles identificadas como muito pobres ou indigentes, afetando principalmente aquelas pessoas (como ex-escravos e viúvas) cuja miséria fora engendrada por uma estrutura social injusta, responsável por uma distribuição desigual dos recursos necessários à subsistência.

\section{Considerações finais}

Vimos que as condições de saúde em Alfenas na Primeira República eram muito precárias devido às limitações estruturais da época derivadas, principalmente, da hegemonia de um liberalismo concebido para concentrar renda e poder no topo da pirâmide social, das dificuldades do saber médico para

${ }_{20}$ PMA, Cemitérios, 1902 a 1904, respectivamente p. 3 v e p. 39 v. 
responder eficientemente à maioria dos principais problemas de saúde da época e do caráter incipiente da organização dos serviços de saúde pública.

Assim, a documentação produzida para registrar os sepultamentos nos cemitérios do município de Alfenas revela uma história social dramática, ao apresentar diversos indicadores trágicos das condições da morte de grande parte dos indivíduos sepultados, como a quantidade enorme de crianças mortas, em particular as menores de um ano de idade, de mulheres falecidas por complicações derivadas do parto e de desvalidos esmagados pela miséria, sobretudo da população remanescente da escravidão e de viúvas, várias delas idosas, que acabaram seus dias enterradas sob o estigma da indigência.

O que essa catástrofe social revela, entre outros dramas, é uma sociedade marcada por forte desigualdade, exclusão e pobreza, que, estruturada na ideologia liberal, acabou deixando a maioria das pessoas entregue à roda da fortuna, ao darwinismo social, sem as mínimas garantias constitucionais, sem educação, sem legislação trabalhista e sem previdência social, o que as tornaram mais expostas à miséria e, consequentemente, às doenças que em outra situação poderiam ser evitadas.

Dessa forma, por trás do levantamento elaborado nesta pesquisa, com base nos frios números dos registros dos cemitérios do município de Alfenas, há um soluçar de dor uma de uma gente sofrida, cujos ecos do sofrimento chegaram até nós permitindo refletir sobre o porquê de as pessoas mais frágeis social e etariamente serem as maiores vítimas de uma sociedade socialmente excludente e de uma política economicamente perversa.

Esses ecos, além disso, podem também nos servir, nesse tempo de pandemia, de alerta de como a negligência à saúde pública pode gerar tamanho descalabro mortuário na população, sobretudo quando aliada à ignorância de muitos e à estupidez de tantos que acabam alimentando ainda mais as estatísticas da morte.

Eis, portanto, as conclusões desta pesquisa que talvez possa servir de modelo para novos e mais profundos estudos sobre outros municípios, em uma perspectiva comparada, que poderão ajudar a compreender melhor a relação entre as condições sociais, a incidência de doenças e a mortalidade neste país onde os serviços públicos de saúde, embora tenham avançado muito em relação ao período aqui analisado, ainda deixa muito a desejar. 
Revista Brasileira de História \& Ciências Sociais - RBHCS

Vol. 13 No 26, Janeiro - Junho de 2021

\section{Referências bibliográficas}

ARIÈS, Philippe. História da morte no Ocidente. Rio de Janeio: Francisco Alves, 1977

- História social da infância e da família. Tradução: D. Flaksman. Rio de Janeiro: LCT, 1978.

CARVAlho, José Murilo de. Cidadania no Brasil. Rio de Janeiro: Civilização Brasileira, 2001.

Os bestializados: o Rio de Janeiro e a República que não foi. 3 ed., São Paulo: Cia das Letras, 1996.

CHALOUB, Sidney et al. Artes e ofícios de curar no Brasil. Campinas: Ed. Unicamp, 2003.

Uma história brasileira das doenças,

DEL PRIORE, Mary. História da infância no Brasil. $4^{\text {a }}$ edição. São Paulo: Contexto, 2004.

. (Org.). História das mulheres no Brasil. São Paulo: Contexto, 1997.

DELUMEAU, Jean. História do medo no Ocidente (1300-180o). São Paulo: Cia das Letras, 1989.

EUGÊNIO, Alisson. Verso e reverso da modernidade: a modernização em Alfenas na Primeira República. Curitiba: Brazil Publishing, 2019.

Arautos do progresso: ideário médico sobre saúde pública no Brasil na época do Império. Bauru: Edusc, 2012.

Fontes para o estudo da história de Alfenas. Alfenas: Universidade Federal de Alfenas, 2013.

FERRAZ, Lucimare e BORDIGNON, Maiara. Mortalidade materna no Brasil: uma realidade que precisa melhorar. In: Revista Baiana de Saúde Pública, vol. 36, n. 2, p. 527 - 553, 2012.

FIGUEIREDO, Betânia G (org.). História, ciência e saúde: práticas e saberes (dossiê). Varia, Revista de História da UFMG, vol. 32, 2004.

FRANÇA, Elisabeth e LANSKY, Sônia. Mortalidade infantil: situação, tendências e perspectivas. Brasília: RIPSA _ Informe de situação e tendência: Demografia e Saúde, 2008, (Texto de apoio, texto 3). 
Revista Brasileira de História \& Ciências Sociais - RBHCS

Vol. 13 No 26, Janeiro - Junho de 2021

FREITAS, Marcos Cesar (Org). Historia social da infância no Brasil. $3^{\text {a }}$ edição. São Paulo: Editora Cortez, 2001.

HOCHMAN, Gilberto. A era do saneamento. São Paulo: Hucitec, 1998.

HOLANDA, Sérgio Buarque de. Raízes do Brasil. São Paulo: Cia das Letras, 1997.

LENHARO, Alcir. As tropas da moderação: o abastecimento da corte na formação política do Brasil, 1808-1842. São Paulo: Símbolo, 1979.

MARTINS, Liane Maria Bertucci. Gripe espanhola: da casa ao hospital In: NASCIMENTO, Dilene Raimundo e CARVALHO, Diana Maul de. Uma história brasileira da doença, vol. 1, Brasília: Paralelo 15, 2004, pp. 165181.

LEAL, Victor Nunes. Coronelismo, enxada e voto. 3 ed., Rio de Janeiro: Nova Fronteira, 1997.

MOORE JR., Barrigton. Origens sociais da ditadura e da democracia. São Paulo, Martins Fontes, 1975

NASCIMENTO, Dilene Raimundo. Tuberculose: alvo da filantropia no início do século XX Rio de Janeiro. In: FRANCO, Sebastião Pimentel et al. Uma história brasileira da doença, vol. 4, Belo Horizonte: Fino Traço, 2013, p. 205-2018.

e CARVALHO, Diana Maul de. Uma história brasileira da doença, vol. 3, Belo Horizonte: Argumentum, 2010.

, CARVALHO, Diana Maul de e MARQUES, Rita de Cássia. Uma

história brasileira da doença, vol. 2, Rio de Janeiro: Mauad X, 2006. e CARVALHO, Diana Maul de. Uma história brasileira da doença, vol. 1, Brasília, Paralelo 15, 2004.

OMRAN, Abdel R. Epidemiological transition in the US: the health factor in population change. Population Bulletin, vol. 32, n, 2, 1977, p. 1-42.

PALLONI, Alberto. Health levels andcare in Latin America: the caseof infant mortality 1900-1985. Populations studies: a journal of demography, London, vol. 45, n. 4, p. 5-20, 1991.

PORTO, Ângela. Tuberculose: a peregrinação em busca da cura e de uma nova sensibilidade. In: NASCIMENTO, Dilene Raimundo e CARVALHO, Diana Maul de. Uma história brasileira da doença, vol. 1, Brasília: Paralelo 15, 2004, p. 91-108. 
Revista Brasileira de História \& Ciências Sociais - RBHCS

Vol. 13 No 26, Janeiro - Junho de 2021

REIS, João José. A morte é uma festa: ritos fúnebres e revolta popular no Brasil do século XIX. São Paulo: Cia das Letras, 1991.

RIBEIRO, Dimas dos Santos. Cemitérios sem mistérios: a arte tumular do sul de Minas (1890-1925). Alterosa: edição do autor apoiada por Furnas de acordo com a lei de incentivo à cultura, 2006.

RODRIGUES, Claúdia. Lugares dos mortos na cidade dos vivos. Rio de Janeiro: Secretaria Municipal de Cultura, 1997.

SAES, Alexandre Macchione et al. O sul de Minas em transição: a formação do capitalismo na passagem para o século 20. Bauru: Edusc, 2012.

SANTOS, Ana Paula Vidal et al. Produção científica sobre mortalidade materna em periódicos de enfermagem. In: Revista Baiana de Enfermagem, vol 24, n. 1, p. 81-86, 2010.

SANTOS, Ricardo Augusto. Representações sociais da peste e da gripe espanhola. In: NASCIMENTO, Dilene Raimundo e CARVALHO, Diana Maul de. Uma história brasileira da doença, vol. 1, Brasília: Paralelo 15, 2004, p. 126-144.

SILVEIRA, Anny Jackeline Torres da. A crônica da espanhola em Belo Horizonte. In: NASCIMENTO, Dilene Raimundo e CARVALHO, Diana Maul de. Uma história brasileira da doença, vol. 1, Brasília: Paralelo 15, 2004, p. 145-164.

SIMÕES, Celso Cardoso da Silva. A mortalidade infantil na transição da mortalidade no Brasil. Belo Horizonte: tese em demografia, UFMG/CEDEPLAR, 1997.

VENÂNCIO, Renato P. Famílias abandonadas: assistência à criança de camadas populares no Rio de Janeiro e em Salvador nos séculos XVVIII e XIX. Campinas: Papirus, 1999.

VIOTTI, Emíla da Costa. Da Monarquia à República: momentos decisivos. 3 ed.,São Paulo: Brasiliense, 1985.

VOLVELE, Michel. Pieté barroque et descrhistianization en Provence au XVIIIeme siécle. Paris: Edition Seuil, 1978.

Recebido em Maio de 2021 Aprovado em Maio de 2021 